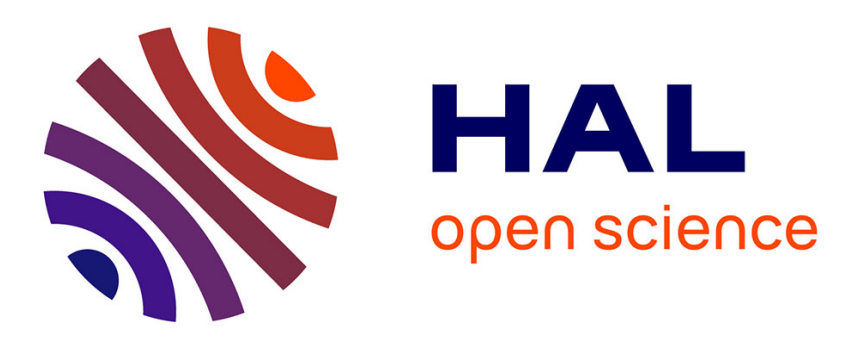

\title{
Optimization of hospital stay through length-of-stay-oriented case management: an empirical study
}

Florian Kainzinger, Christian A. Raible, Konstantin Pietrek, Jacqueline Müller-Nordhorn, Stefan N. Willich

\section{To cite this version:}

Florian Kainzinger, Christian A. Raible, Konstantin Pietrek, Jacqueline Müller-Nordhorn, Stefan N. Willich. Optimization of hospital stay through length-of-stay-oriented case management: an empirical study. Journal of Public Health, 2009, 17 (6), pp.395-400. 10.1007/s10389-009-0266-5 . hal-00535282

\section{HAL Id: hal-00535282 \\ https://hal.science/hal-00535282}

Submitted on 11 Nov 2010

HAL is a multi-disciplinary open access archive for the deposit and dissemination of scientific research documents, whether they are published or not. The documents may come from teaching and research institutions in France or abroad, or from public or private research centers.
L'archive ouverte pluridisciplinaire HAL, est destinée au dépôt et à la diffusion de documents scientifiques de niveau recherche, publiés ou non, émanant des établissements d'enseignement et de recherche français ou étrangers, des laboratoires publics ou privés. 


\title{
Optimization of hospital stay through length-of-stay-oriented case management: an empirical study
}

\author{
Florian Kainzinger • Christian A. Raible • \\ Konstantin Pietrek • Jacqueline Müller-Nordhorn • \\ Stefan N. Willich
}

Received: 1 September 2008 / Accepted: 23 February 2009/Published online: 9 April 2009

(C) Springer-Verlag 2009

\begin{abstract}
Background and objectives An important component of efficient and high-quality treatment of patients under DRG conditions is the control of patients' length of stay in hospitals. Medical processes need to be structured in such a way that unnecessary extensions of the length of stay are avoided, thus achieving an economically and qualitatively optimal result. The study presented here examines the question of whether the introduction of length-of-stayoriented case management can optimize the duration of patients' hospital stays.

Methods In total, 168 inpatient cases and their matched control cases from the cardiology and urology stations of a maximum care hospital are examined in this study.

Results The result of the t-test for the difference of means indicates that the average length of stay of the intervention cases (5.79 days) was significantly shorter than the average length of stay of the control cases (7.34 days). With respect to the re-admission rate, a statistically significant dependence could not be determined.
\end{abstract}

F. Kainzinger $(\bowtie) \cdot J$. Müller-Nordhorn $\cdot$ S. N. Willich Institute for Social Medicine, Epidemiology, and Health Economics, Charité University Medical Center Berlin, Charité,

CCM D- 10098 Berlin, Germany

e-mail: florian.kainzinger@charite.de

C. A. Raible

Helmholtz Zentrum München, Institute of Health Economics and Health Care Management,

Munich, Germany

K. Pietrek

Department of Finance, University of Maastricht, Maastricht, The Netherlands
Discussion and conclusion The operationalization of case management in daily clinical routines was tested by a comprehensive survey. Length-of-stay-oriented case management provides transparency of the entire treatment process and integrates procedures to an optimal extent. However, the doctor's sovereignty over therapy is not affected by the introduction of length-of-stay-oriented case management. Hence, the form of case management presented here serves as a new and innovative control and monitoring system for hospitals, as it makes institutions that implement such a system more competitive through the improvement of economical aspects as well as through the introduction of higher process efficiency.

Keywords Case management - Length of stay · Reduction . Hospital P Process optimization $\cdot$ Controlling

\section{Introduction}

With the introduction of the lump sum-based reimbursement model in German hospitals (G-DRG) in 2003, the stimulus and competitive structure in this market have fundamentally changed. The realignment within the German hospital system has led to a stronger orientation among individual market participants towards economic as well as qualitative criteria.

An important component of an efficient and high-quality treatment under DRG conditions is the control of inpatients' lengths of stay in a hospital. Compared inernationally, the duration of inpatient stay in German hospitals is rather high, taking into account the haziness inherent in such considerations (OECD 2006). As a matter of fact, excessively long turnaround times, caused by unsynchronized processes, do not lead to any — or only to marginal— 
additional revenue under the currently valid reimbursement system. Additionally, those turnaround times block valuable resources for the treatment of other patients. It is undeniably important to avoid (short) inpatient stays below the lower length-of-stay threshold in order to circumvent a threatened revenue reduction that could occur, but also on the other hand to avoid the danger of a medically induced re-admission of a patient. Therefore, within the context of maximum patient satisfaction, one must not lose sight of economic considerations or of qualitative aspects.

Generally, a patient is looking for a hospital stay that is as short as possible. Hence, medical processes should also be structured in such a way that unnecessary extensions of hospital stays can be avoided in order to achieve an optimal result, both economically and qualitatively. A commensurate control of the treatment process can be described as case management.

The term case management originated in the USA and dates back to the second half of the nineteenth century (Olivas et al. 1989a, b; Ethridge 1991; Tahan 1998). Apart from various existing definitions (Cudney 2002; Zander 2002), the internationally most widely used description characterizes case management as a "collaborative process of assessment, planning, implementation, coordination, monitoring and evaluation" of health services with the objective "to fulfill the health needs of an individual through communication and the provision of resources, and to ensure high-quality and cost-effective treatment successes" (Powell and Ignatavicius 2001).

A large number of scientific investigations have already been undertaken within the broad spectrum of case management. Studies from within the Anglo-American region examine the effects of case management on different hospital indicators. Here, various studies on changes in inpatient stays caused by case management in hospitals have been reviewed and analyzed (Shi 1996; Bennett et al. 1997; Roddy et al. 1998; Terra 2007). Bennett et al. showed a 50 percent reduction in length of stay by using case management in neurology departments without affecting the treatment quality. In another study, Roddy et al. were able to prove a 66 percent reduction in length of stay within a 4-year period in a vascular surgery department. Other studies include the use of intensive care units and patient mortalities (Walters et al. 1998), treatment costs (Woods et al. 1992) as well as unjustified procedures and the willingness of insurance companies to pay (Daniels 1999). All in all, medical as well as economic effects after introducing case management could be found (Yamamoto and Lucey 2005).

In Germany, more recent research concerning case management has placed strong emphasis on nursing care and social aspects (Ewers and Schaeffer 2000; Wendt 2002; Löcherbach 2003). However, previous investigations often concentrated only on individual indications, specialist areas or clinics, without developing a comprehensive system of case management (Lehmann and Köpfer 2002; Krusch et al. 2006).

In their investigation on institutional framework conditions for the introduction of systematic case management in hospitals, Roggenkamp et al. called for investigating various forms of case management more closely in order to draw conclusions about their influence on economic and qualitative results (Roggenkamp et al. 2005). The study presented here followed this recommendation, and we first designed an expertise-overlapping system of case monitoring that did not focus solely on one medical specialization and that concentrated especially on parameters associated with the duration of hospital stays. Thereafter, we consider whether the introduction of length-of-stay-oriented case management can optimize the stay of inpatients in a hospital.

\section{Method}

\section{Description of intervention}

In order to standardize the control process described above, a special form of case control was developed, length-ofstay-oriented case management. This particular form of case management has the objective to ensure that patients who need to be treated within the framework conditions of the German DRG system (G-DRG) are medicated in an economical and at the same time very highly qualitative way, by maintaining the optimal length of stay. The case manager has a professional medical background (usually nursing staff) and does not have other responsibilities besides case management. Hence, three main tasks of length-of-stay-oriented case management can be identified: the avoidance of unjustified procedures, raising transparency to ensure an optimal duration of time, and efficient discharge management. Therefore, the case manager can make an assessment of the patient already before the onset of any stationary treatment. This ensures compliance with the criteria according to the Appropriateness Evaluation Protocol (AEP) (Gertmann and Restuccia 1981). The AEP is a standardized data entry form that helps to evaluate the necessity of stationary treatment for patients. Hence, reimbursement reductions by medical insurers with the justification of non-acceptance of inpatient treatment are avoided. Furthermore, on the very first treatment day, the case manager generates (in close agreement with the attending doctor) a preliminary principal diagnosis and then supplements it as required with ancillary diagnoses and procedures. Consequently, right from the start of a treatment, a DRG is available for each patient. Usually, a 
diagnosis is documented in most of the hospitals in Germany on the first day. Contrary to the new form of length-of-stay-oriented case management, usually the hospital information system is not used to group a patient's individual DRG right from the first inpatient day. Moreover, on the first treatment day a discharge target day is determined, based on the framework data of the respective DRG. In order to create maximum transparency among doctors, nursing staff and functional areas, each patient file is given a notation daily, including the patient's DRG, the actual duration of the stay, lower and medium inpatient duration limits, and the target discharge day. Within daily consultations among all professions at the treatment station, a patient's actual and targeted stays are compared with each other, and courses of action are examined. If required, new findings on particular patients can be taken into account with supplementary codes as well as the initialization of a transfer of care or specific social services. After the completion of patient treatment the case manager also serves as contact person for the medical controlling of health insurers, for example, in case of reimbursement discussions (Fig. 1).

However, it must be emphasized that the described form of case control does not cover the entire scope of the definition given by Powell and Ignatavicius cited above. For instance, the case manager of a normal case does not have personal contact with the patient, but instead works in the background. Moreover, length-of-stay-oriented case management follows the target functions of the hospital, and therefore it cannot be used alone as a gauge for institution-overlapping patient control (Wissert 2006).

Study design, matching and analytical procedure

The study presented here is essentially a retrospective case control study, taking place at the cardiology and urology stations of a maximum care communal hospital. Those two departments were chosen to examine a non-surgical as well as a surgical unit. For the intervention by means of length- of-stay-oriented case management, there was no limitation on certain indications or TOP-DRGs within a respective specialist area. Within the full survey and without specific inclusion and/or exclusion criteria being defined, 259 patients with a 5-week intervention period were included in the study. For the evaluation of the data obtained, respective controls were added to the intervention cases. In order to achieve the best possible matches between cases and controls, the following parameters were included: specialist department, DRG, patient's co-morbidity and complexity levels (PCCL), age (separation into four categories: 0-14, 15-35, 36-65 and over 65) and sex. Since the intervention was made during the calendar year 2008, and the controls originated in part during the year 2007, all cases were grouped together with the DRG system 2007 in order to achieve a comparable DRG categorization between cases and controls. For the exclusion of other, external influences (e.g., new modern operating procedures or a change in the attending doctor and nursing staff), the controls were filtered out from a 6-week period before the intervention. All data were assessed anonymously. In total, suitable controls were assigned to 168 of the 259 intervention cases $(65 \%)$, which were then used for subsequent analysis.

In order to depict the congruence of intervention and control cases, descriptive statistical methods were used initially for all cases together, as well as separately for respective specialist departments. In order to analyze the difference in respect to a potential change of group-specific lengths of hospital stays, a t-test was used for pairs of observations for differences of means in the duration of hospital stays. In addition, the Wilcoxon test was utilized as a non-parametric procedure in order to validate the results (Fahrmeir et al. 2001). These statistical evaluations were done by means of the SPSS software package, version 16.0.

An indicator for the quality assessment of inpatient care services was the re-admission rate (Kim and Soeken 2005; Southern et al. 2007; Berenholtz et al. 2002). In order to approximately exclude qualitatively inferior medical treat-
Fig. 1 Tasks of the length-ofstay-oriented case manager

OCCUPANCY MANAGEMENT
- Avoidance of unjustified
occupancy by early examination
of AEP criteria
- Disposition of bed capacities for
emergency cases
- Coordinationof bed availabilities

CODING
- Early coding of stationary patients in specialist areas
- Information to doctors and nursing staff about target discharge date
- Documentation of reasons for non-compliance of length-of- stay targets
- Exchange over patients with the MDK (medical controlling by health insurers)

DISCHARGE MANAGEMENT / SOCIAL SERVICES

\footnotetext{
- Admission and bundling of medical, nursing and social anamnesis

- Focused, early inclusion of social services

- Ensure completion of application forms
} 
ment, the quota of returnees was also considered within the analysis. The data were obtained through the hospital information system, considering only re-admissions of intervention and control cases in the hospital included in this study.

\section{Results}

Results of the descriptive statistics method reveal that the 168 intervention cases (which could be matched with suitable controls) consisted of 87 urology and 81 cardiology cases (Table 1). One hundred ten of the 168 intervention cases and controls were male patients, and 58 were female. The average age for all 168 intervention patients (68.5 years) was slightly above the average age of the controls (66.14 years). Also the average age of the urology (64.08 years) and the cardiology (72.32 years) intervention patients was slightly higher in comparison to the urology (62.21 years) and cardiology control patients (71.46 years). A similarly high congruence existed for the degree of severity between the case and control group, with a slightly smaller scattering among the controls (Fig. 2).

The result of the t-test of the difference of means showed that the average duration of hospital stays between intervention patients (5.79 days) and the control patients (7.34 days) was significantly different. The duration of hospital stays could be lowered on average by 1.55 days $(p<0.001)$ (Table 2$)$. Therefore, this result shows a clear reduction in the duration of inpatient stays after the introduction of case management.

To validate the result of the parametric analysis procedure, an additional Wilcoxon-Test was used as a nonparametric procedure. This test also showed a significant reduction in the duration of hospital stays ( $\mathrm{p}<0.001$; not reported here).

As mentioned above, in order to approximately exclude qualitatively inferior medical treatment, the quota of returnees was also considered, in addition to their length of stay. The number of patients with a renewed hospital stay within 30 calendar days was $1.45 \%$ in the control group and $0.60 \%$ in the intervention group. By means of Fisher's exact test, it could be shown that re-admission was independent of intervention and control group, respectively (null hypothesis of independence with a p-value of 0.35 could not be rejected).

\section{Discussion and conclusions}

Studies that involve the effects of certain interventions on the duration of the hospital stay of inpatients must ensure the comparability of intervention and control cases. In contrast to randomized case control studies, whereby, for example, the population can be preselected indicationspecifically, in this study all patients that had been admitted to the participating stations were included in the survey. Hence, the operationalization of length-of-stay-oriented case management was tested in daily, clinical routines, and thus effects of selection were largely avoided. However, to what degree the results obtained can also be utilized in other medical specialist departments (other than cardiology and urology) still needs to be analyzed within the scope of further investigations. Another limitation of this study was the concentration on one medical institution. After designing the specific concept of length-of-stay-oriented case management in this survey, further research projects should be set up in different hospitals to compare the results. These studies should also consider additional quality indicators to ensure the findings of this survey.

By matching intervention cases with control cases that had been selected according to criteria commonly used in scientific studies, largely comparable study groups were available for this study (Juni et al. 2001; Suh et al. 2000). Because of the allocation of controls that were very close in time to the intervention cases, factors that could influence the study, such as doctors scheduled to attend, the treatment and possible modifications in the area of therapy, could be limited.

Therefore, it can be concluded that the intervention of length-of-stay-oriented case management investigated in this study carried out the primary task of creating transparency in the overall treatment process and thus integrated procedures optimally. Strikingly, the doctors'
Table 1 Results of the descriptive statistics

$\mathrm{M}=$ male
$\mathrm{F}=$ female
$\varnothing=$ mean
$\mathrm{SD}=$ standard deviation
$\mathrm{Min}=$ minimum
$\mathrm{Max}=$ maximum

\begin{tabular}{|c|c|c|c|c|c|c|c|}
\hline \multirow[t]{2}{*}{ No. } & \multirow[t]{2}{*}{ No. } & \multicolumn{2}{|l|}{ Sex } & \multicolumn{4}{|l|}{ Age } \\
\hline & & M & $\mathrm{F}$ & $\varnothing$ & SD & Min & Max \\
\hline Intervention cases total & 168 & 110 & 58 & 68.05 & 15.59 & 20 & 97 \\
\hline Control cases total & 169 & 110 & 58 & 66.14 & 15.13 & 15 & 96 \\
\hline Intervention cases urology & 87 & 67 & 20 & 64.08 & 16.97 & 20 & 89 \\
\hline Control cases urology & 87 & 67 & 20 & 62.21 & 16.30 & 15 & 95 \\
\hline Intervention cases cardiology & 81 & 43 & 38 & 72.32 & 12.72 & 43 & 97 \\
\hline Control cases cardiology & 81 & 43 & 38 & 71.46 & 11.46 & 36 & 96 \\
\hline
\end{tabular}


Fig. 2 Degree of severity of intervention and control cases

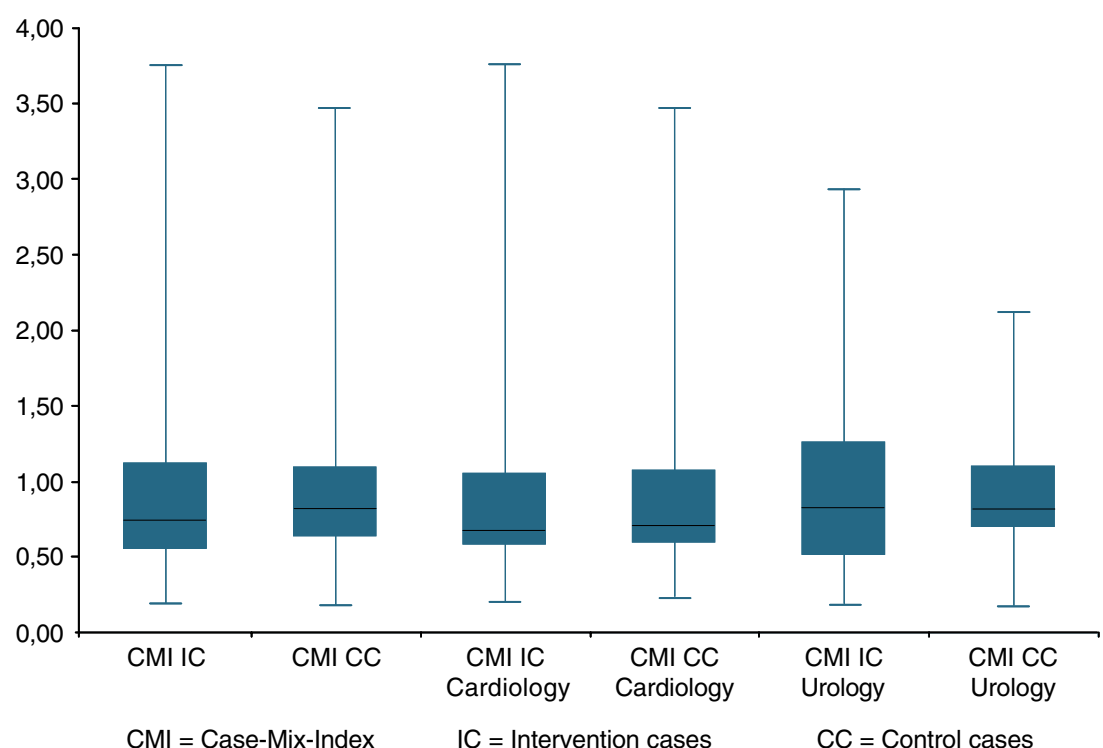

$\mathrm{CMI}=$ Case-Mix - Index sovereignty over therapy remained unaffected, and medical decisions were not made without them. Hence, no inpatient was given inferior treatment because of length-of-stayoriented case management. What is important is the fact that there is merely better coordination of the treatment process with positive effects on the cost effectiveness of a hospital. Because of the support activity of the case manager, the doctor is relieved of administrative tasks such as coding or documentation.

Moreover, the study discussed here was able to prove that length-of-stay-oriented case management can lower the hospital stay of inpatients (in the facility studied here) by more than $21 \%$, without increasing the number of returnees. If one considers that this investigation only involved one primary phase of two normal care stations of a maximum care hospital and that the method has not yet been extended to the entire treatment process (including, among others, out-patient treatment and intensive care stations), as well as to the overlap between specialist departments, the results of the initially discussed studies by Roddy et al. (reduction of hospital stay by about $66 \%$ ) and Bennett et al. (reduction of hospital stay by about $50 \%$ ) might also be achieved here.

Table 2 The t-test results of difference of means of length of stay

\begin{tabular}{lccccc}
\hline & No. & $\varnothing$ & $\mathrm{S}^{2}$ & $\emptyset_{\mathrm{K}-1}$ & $\mathrm{p}$-value \\
\hline Control ceses & 168 & 7.34 & 14.63 & $1.55^{* * *}$ & $<0.001$ \\
Intervention cases & 168 & 5.79 & 15.99 & & \\
\hline
\end{tabular}

No. $=$ number

$*, * *, * * *$ Mean value difference significant at $5 \%, 1 \%, 0.1 \%$

$\varnothing=$ mean value

$\mathrm{S}^{2}=$ variance

$\varnothing_{\mathrm{K}-1}=$ difference of mean values
This applies particularly when one considers that the US studies sometimes extended over a 4-year period, which then facilitated the implementation of significant learning effects in the system.

Furthermore, extrapolating the reduction in length of stay in the specialist departments cardiology and urology included in this study to the actual annual case numbers of the clinics and then taking into account only that percentage of the patient component analyzed here by means of matching, one obtains a potential reduction of 4,301 occupancy days. With an average occupancy load of $85 \%$, length-of-stay-oriented case management opens up the possibility of treating an additional (approximately) 631 patients (498 for $\varnothing$ length-of-stay control cases, according to Table 2) with the same capacities. The treatment of these additional patients would create an average revenue of $€$ 2,800 per patient for a total of $€ 1.76$ million ( $€ 1.39$ million) for the hospital used in this study. A number of additional cost components that are service volumeinduced, such as the medical supplies required, need to be taken out of the revenue and cost calculations. Existing staff and infrastructure elements are working adequately to capacity through the optimization of the length of inpatients' hospital stays. Finally, such optimization leads to distinctly positive operating results for the respective clinics. However, prerequisites for this are that (1) there is enough patient demand to fill the freed up hospital capacity and (2) there is sufficient excess capacity among medical and nursing staff, as well as in diagnostic and therapeutic units, so that additional inpatients can be cared for without staff increases and infra-structural expansions.

In case that the demand for medical services in these areas does not permit the admission of additional patients to a clinic or that an expansion of services within the existing funding 
system cannot be arranged with health insurance companies, the treatment control presented here enables a reduction of patient beds. Hence, it leads to savings on diverse cost components with an unaffected revenue situation.

Both optimization possibilities depicted here-increased revenue as well as providing cost reductions-lead to additional profit contributions for the hospital and to an increase in productivity (Kuntz et al. 2007). With foreseeable changes in the funding to service providers in the German health system, e.g., the introduction of monistic financing, the generation of additional revenue would gain successively in significance, and hospitals would thus be able to pay for medical innovations through their own efforts (e.g., installing expensive new medical devices or financing building investments for process improvements). Therefore, the type of case management presented here provides a foundation for a monitoring and control system of a hospital. This could make institutions that use case management permanently competitive by improving economic aspects and qualitative processes.

Acknowledgements We would like to express our gratitude to the staff of the hospital departments where this study was conducted, as well as to the patient administration at the Dr. Horst Schmidt Clinic of the City of Wiesbaden. In particular, we would like to thank the accompanying clinic directors, Dr. Klaus Kleinschmidt and Dr. Martin Sigmund for their strong support. We would also like to thank Dr. Reiner Leidl (Helmholtz Center Munich) for his advice on earlier versions of this paper.

Conflict of interest disclosure The authors disclose any relevant associations that might pose a conflict of interest.

\section{References}

Bennett PJ, Fosbinder D, Williams M (1997) Care coordination in an academic medical center. Nurs Case Manag 2(2):75-82

Berenholtz SM, Dorman T, Ngo K, Pronovost PJ (2002) Qualitative review of intensive care unit quality indicators. J Crit Care 17 (1): $1-12$

Cudney AE (2002) Case management: a serious solution for serious issues. J Healthc Manag 47(3):149-152

Daniels S (1999) Using hospital-based case management to reduce payer denials. Healthc Financ Manage 53(5):37-39

Ethridge P (1991) A nursing HMO: Carondelet St. Mary`s experience. Nurs Manag 22(7):22-27

Ewers M, Schaeffer D (2000) Case management in Theorie und Praxis. Huber, Bern

Fahrmeir L, Künstler R, Pigeot I et al (2001) Statistik-Der Weg zur Datenanalyse, 3rd edn. Springer, Berlin

Gertmann PM, Restuccia JD (1981) The appropriateness evaluation protocol: a technique for assessing unnecessary days of hospital care. Med Care 19(8):855-871

Juni P, Altman D, Egger M (2001) Systematic reviews in health care: assessing the quality of controlled clinical trials. BMJ 323 (7303):42-46

Kim YJ, Soeken KL (2005) A meta-analysis of the effect of hospitalbased case management on hospital length-of-stay and readmission. Nurs Res 54(4):255-264
Krusch A, Siegmund T, Huber P, Kircher M, Schumm-Draeger PM (2006) Clinical Pathways und case-Management als DRGManagementinstrumente. Das Krankenhaus 124-128

Kuntz L, Scholtes S, Vera A (2007) Incorporating efficiency in hospital-capacity planning in Germany. Eur $\mathrm{J}$ Health Eco 8 (3):213-223

Lehmann U, Köpfer T (2002) DRGs als Rahmen für strukturelle Neuerungen im Krankenhaus-Beispiel: case-manager im Unfallkrankenhaus Berlin. Electromedica 70(2):116-118

Löcherbach P (2003) Einsatz der methode case management in Deutschland: Übersicht zur Praxis im Sozial- und Gesundheitswesen. In: Porz F, Erhardt H (eds) Neue Wege in der Nachsorge und Palliativversorgung. BetaInstitutsverlag, Augsburg, pp 20 33

OECD (Organisation for Economic Co-operation and Development) (2006) OECD Health Data 2006. Paris

Olivas GS, Del Togno-Armanasco V, Erickson JR et al (1989a) Case management: a bottom-line care delivery model, Part I. J Nurs Adm 19(11):16-20

Olivas GS, Del Togno-Armanasco V, Erickson JR et al (1989b) Case Management: A bottom-line care delivery model, Part II. J Nurs Adm 19(12):12-17

Powell SK, Ignatavicius D (2001) Core curriculum for case management. Lippincott, Philadelphia

Roddy SP, O'Donell TF, Iafrati MD, Isaacson LA, Bailey VE, Mackey WC (1998) Reduction of hospital resources utilization in vascular surgery: a 4-year experience. J Vasc Surg 27(6):10661075

Roggenkamp SD, White KR, Bazzoli GJ (2005) Adoption of hospital case management: economic and institutional influences. Soc Sci Med 60:2489-2500

Shi L (1996) Patient and hospital characteristics associated with average length of stay. Health Care Manag Rev 21(2):46-61

Southern WN, Berger MA, Bellin EY et al (2007) Hospitalist care and length of stay in patients requiring complex discharge planning and close clinical monitoring. Arch Intern Med 167(17):18691874

Suh DC, Woodall BS, Shin SK et al (2000) Clinical and economic impact of adverse drug reactions in hospitalized patients. Ann Pharmacother 34(12):1373-1379

Tahan HA (1998) Case management: a heritage more than a century old. Nurs Case Manag 3:55-60

Terra SM (2007) An evidence-based approach to case management model selection for an acute care facility: is there really a preferred model? Prof Case Manag 12(3):147-57

Walters J, Schwartz CF, Monaghan H, Watts J, Shlafer GJ, Deeb GM, Bolling SF (1998) Long-term outcome following case management after coronary artery bypass surgery. J Card Surg 13 (2): $123-128$

Wendt WR (2002) Case management-stand und Positionen in der Bundesrepublik. In: Löcherbach P, Klug W, RemmelFaßbender R, Wendt WR (eds) Case management - fall- und systemsteuerung in Theorie und Praxis. Luchterhand, Neuwied, pp 13-36

Wissert M (2006) Clinical pathways-entlassungsmanagement-unterstützungsmanagement, begriffserklärung und Systematisierung ausgewählter case management-strategien. Case Manag 2 (1):35-38

Woods JR, Saywell RM, Nyhuis AW, Jay SJ, Lohrman LG, Halbrook HG (1992) The learning curve and the cost of heart transplantation. Health Serv Res 27:219-238

Yamamoto L, Lucey C (2005) Case management "within the walls": a glimpse into the future. Crit Care Nurs Q 28(2):162-178

Zander K (2002) Nursing case management in the 21st century: intervening where margin meets mission. Nurs Administration Q 26(5):58-67 